\title{
The Age of Initiation of Drug Use and Sexual Behavior May Influence Subsequent HIV Risk Behavior: A Systematic Review
}

\author{
Patrick Baldwin, Roman Shrestha, Jessica Potrepka, and Michael Copenhaver \\ University of Connecticut, Department of Allied Health Sciences, 358 Mansfield Road, Unit 2101, Storrs, CT 06269-2101, USA \\ Correspondence should be addressed to Michael Copenhaver; michael.copenhaver@uconn.edu
}

Received 10 September 2013; Accepted 8 October 2013

Academic Editors: D. Aunis, H. C. Mwandumba, and J. Poudrier

Copyright (C) 2013 Patrick Baldwin et al. This is an open access article distributed under the Creative Commons Attribution License, which permits unrestricted use, distribution, and reproduction in any medium, provided the original work is properly cited.

\begin{abstract}
Researchers examining injection drug users (IDUs) in drug treatment have been trying for decades to determine the optimal way to intervene to prevent the transmission and spread of human immunodeficiency virus (HIV) in this population. Although efficacious HIV risk reduction interventions are widely available, questions remain about what specific factors are most related to HIV risk behavior and defined as unprotected sexual activity and/or high risk drug use. This review involved an evaluation of the research literature in order to better understand the association between drug use and sexual behavior debut on HIV risk behavior. Findings suggest that drug use debut and sexual behavior debut may be related to subsequent HIV risk behavior. Evidence to date implies that intervening at an earlier age to assist youth to avoid or delay these high risk behaviors may be an additional means of reducing subsequent HIV risk.
\end{abstract}

\section{Introduction}

Globally, an estimated 3 million people who inject drugs are living with HIV, representing roughly one in 10 infections worldwide [1]. An estimated 49,273 individuals in the U.S. were infected with HIV in 2011 and injection drug users (IDUs) remain at high risk for HIV transmission. Since the epidemic began, nearly 182,000 injection drug users with an AIDS diagnosis have died, including an estimated 4,218 in 2010. Of the approximate 32,050 new cases of AIDS reported in 2011, 3,961 were IDU-associated. In 2011, 7.4\% of all newly diagnosed cases in adults and adolescents were from IDUassociated behavior [2]. With the high rate of HIV risk in the IDU population, it is even more important to understand the events leading to risk behavior.

Part of the global HIV epidemic involves adolescents who are initiating sexual activity at progressively earlier ages [3] and putting themselves and others at increased risk for HIV infection. A 2011 CDC survey found that $47 \%$ of high school students reported having sexual intercourse, $6.2 \%$ reported having intercourse before age 13, and an alarming 39.8\% reported not using a condom during their last intercourse [4]. The average reported age of first sexual intercourse in the USA is age 14.4, with more males than females $(9.0 \%$ versus $3.4 \%$, resp.), and more African-American teens than other racial/ethnic groups reporting sexual activity before age 13 -highlighting a common racial disparity pattern $[4,5]$. Although data exist regarding HIV risk and prevalence rates, questions remain about what factors are most predictive of subsequent HIV risk behavior among adolescents and young adults, and thus what strategies could potentially alter this trajectory.

While research has focused on identifying predictors of risk behaviors in adolescence, the influence of the age of debut, defined as the initiation or the first occurrence of certain behaviors such as substance use and coitus, on later HIV risk outcomes remains largely unexplored in the empirical research literature. Health behavior research to date has examined how the debut of specific risk behaviors among youth is predictive of various negative health outcomes among those individuals later in life as adults [6-15]. For example, early sexual debut has been linked to short-term negative outcomes such as higher levels of depression among adolescents [16] and delinquency [17], as well as longer-term negative outcomes including lowered expectations for pursuing higher education $[18,19]$, poorer 
academic performance [20], less consistent contraceptive use [21], unintended pregnancies [14], increasingly risky sexual behaviors [22-35], and likelihood of having multiple partners [36-38]. Conversely, other studies indicate that the delay of sexual initiation tends to be protective of future risk behavior $[3,16,18,39]$.

There are clear parallels between sexual debut and substance use debut in terms of the potential pattern of influences on subsequent health risks. A growing number of studies have also been concerned with the linkage between early onset of drug use and a range of negative health risk outcomes that occur in adulthood. For example, an earlier age of substance use debut is a well-documented risk factor for subsequently developing substance use disorders $[13,40-$ 48], poorer academic performance, and lower academic expectations $[48,49]$. Drug use debut and HIV transmission risk behavior have also been tentatively linked in several recent studies [50-55], although this linkage was not the primary focus of these studies.

Like other types of substance use in adolescence, drinking alcohol at an early age remains a serious health concern since it may interfere with brain development and lead to cognitive and behavioral dysfunctions that foster risk taking [56] and later substance use problems $[6,57]$. Early onset of alcohol consumption may also tend to establish a pattern of maladaptive coping mechanisms in which alcohol is implemented to manage stress [44]. Furthermore, substance use-particularly heavy drug use-during a critical period of neurobiological development may lead to poorer memory and learning functioning, reduced inhibition, abnormalities in executive functioning and neuronal activation, and alterations in brain structure, as well as a host of other neurocognitive sequelae [58].

In addition to the parallels between drug use debut and sexual debut, numerous studies have highlighted a cooccurrence of both behaviors, linking the debut of one type of behavior to the other, or both, and underscore their complex and often interwoven associations [20, 5964]. For example, one investigation of Swedish high school students found that teens who reported sexual debuts at age 15 used more tobacco, illicit drugs, and alcohol than their aged-matched inexperienced peers, suggesting a clustering of risk behaviors linked with early sexual initiation [65]. By systematically exploring the relevant literature in the present review, we seek to more clearly elucidate the progression of HIV risk behaviors over time so as to better inform future HIV prevention interventions.

\section{Methods}

2.1. Selection of Studies. We searched for studies that included quantitative data about sexual debut, drug use debut, and subsequent HIV risk behavior. In conducting this literature review, peer-reviewed studies were included if they met all of the following criteria: (1) identified either age of sexual debut, age of substance use debut, or both; (2) assessed at least one concurrent or subsequent HIV-related substance use or sexual risk behavior as an outcome; and (3) were published in English (see Figure 1).

2.2. Search Strategy. An extensive literature search was conducted in the online database PubMed that included studies from 2001 through December, 2012. Our primary objective was to review scientific data related to the influence of both sexual and substance use debut on subsequent HIV risk behavior. We cross-referenced previous reviews and primary studies for additional citations. In an initial search, both of our domains, drug use debut and sexual debut, were crossed one-at-a-time with consequential HIV risk behavior, using multiple combinations of search terms; see Table 1.

The search was not limited to any particular geographic area or region and there were no restrictions imposed on the age of subject populations. As such, definitions of "early debut" of either risk behavior varied across studies, making preadolescence, adolescence, and young adulthood more useful terms that would ensure coverage of all target groups and encompass a broader age range. Sexual debut was defined as first oral, anal, or vaginal sex. Substance use included all illicit drugs, cannabis, alcohol, and tobacco. HIV risk behavior outcomes included unprotected sexual activities, sexual activities under the influence of drugs and/or alcohol, sex with multiple partners, exchange sex, injection drug use (IDU) - particularly using uncleaned syringes or sharing injection equipment, sex with an IDU partner or partners, STI, pregnancy, and HIV serostatus.

A total of 1,469 articles were retrieved as of December 30, 2012. Thirteen additional articles were found in the reference section of the relevant journal articles. After the removal of 318 duplicated records, 1,164 articles remained for preliminary review. After inspecting study titles and abstracts, we found that 920 records were not directly relevant to the study objectives, leaving 244 records for further, more detailed, review. A full-text copy of this subset of studies was obtained and assessed for inclusion. 187 full-text records were excluded because they did not investigate an association between the variables of interest and behavioral outcomes that constitute HIV risk behaviors. Finally, a total of 57 studies were included for this review (see Figure 1).

\section{Findings}

3.1. Early Initiation of Sexual Behavior and Concurrent Health Risks. Early initiation of sexual behavior is viewed as a health risk since youth who initiate sexual behavior at an earlier age spend relatively more years at potential risk for HIV and a range of other sexually transmitted diseases versus those who are not sexually active until a later point. One study found that among a sample of female high school students in Nova Scotia, aged 15 to 19, having vaginal intercourse before 15 years was associated with sexual risk-taking behaviourssuch as not using a condom, unplanned intercourse due to substance use, having a casual partner, and having multiple sexual partners-at later points in adolescence [78]. Similarly, Pettifor et al. evaluated risk factors related to early coitarche among 7,692 South African youth and found that $18 \%$ of males 


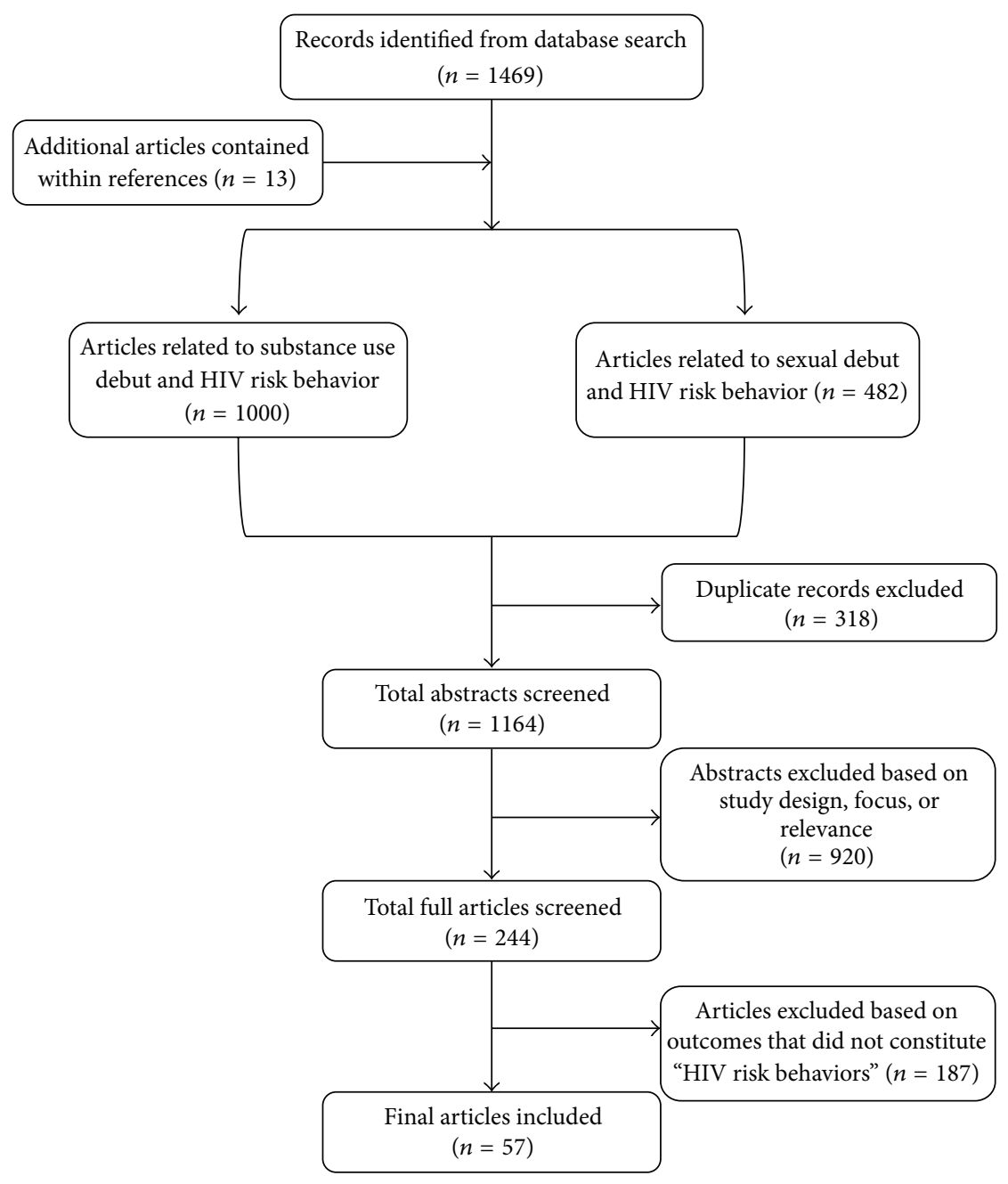

FIGURE 1: Study inclusion flow diagram.

and $8 \%$ of females reported sexual debut at age 14 or younger [91], while a cross-sectional study of homeless 13- to 17-year olds in Brazil revealed that one-third of females and twothirds of males in the sample reported sexual debuts under the age of twelve [68]. An earlier sexual debut was associated with inconsistent condom use [68] and a lack of condom use [91].

Nkansah-Amankra et al. examined data from the Colorado Youth Risk Behavior Surveillance System (2005) sampling 1,498 adolescents in 29 public schools, grades 912-and found an association between patterns of adolescent drug use and high risk sexual behavior [85]. Females in the sample who reported using two illegal substances were 12 times more likely to report early sexual debuts than those reporting no use, while females using three substances were 44 times more likely to report early sexual debuts. Additionally, adolescent binge drinking was also associated with higher odds of having multiple partners. The results suggested that adolescents with drug-use experience had a greater tendency to report being involved in high risk sexual activity and consequently to be at greater risk for contracting and spreading HIV.
In a seven-year cohort study of American Indian teens aged 14-18 living in a Northern Plains community in South Dakota, Mitchell et al. (2007) found that while predictors of early sexual initiation differed by gender, having used alcohol or drugs at sexual debut was a significant predictor of early sexual initiation for both males and females [82] as other researchers have found $[20,62]$. Still another investigation showed that young men in rural South Africa reporting sexual debut before age 15 were more likely to not use condoms at first sex and to have had multiple and casual partners than those who had initiated sex at 15 or older [28]. Likewise, a later investigation revealed that sexual debuters aged 16 and younger, particularly males reporting female partners, were more likely to have had multiple sexual partners than later debuters-highlighting a similar, albeit gender-specific, combination of risky behaviors occurring at sexual debut [35].

Thus, there is evidence from diverse samples that, not surprisingly, earlier initiation of sexual behavior among youth is linked with higher levels of concurrent health risk behaviors among these samples. A similar pattern of findings have been identified with regard to health risks associated 
TABLE 1: Search terms and terminology used for retrieval of eligible citations and reports.

\begin{tabular}{|c|c|c|}
\hline \multicolumn{2}{|c|}{$\begin{array}{l}\text { "risk behavior" AND "initiation" AND "subsequent" } \\
\text { "drug initiation" OR "sexual initiation" AND "risk" AND "HIV" }\end{array}$} & $\begin{array}{l}\text { " AND "risk" } \\
\text { ut" AND "HIV" } \\
\text { on" AND "subsequent" } \\
\text { on" AND "risk" AND "HIV” }\end{array}$ \\
\hline $\begin{array}{l}\text { "Substance use" OR "drug use" OR "needle sharing" OR "syringe } \\
\text { sharing" OR "first injection" OR "drug initiation" OR "IDU" }\end{array}$ & AND & $\begin{array}{l}\text { "age of initiation" OR “age of debut" OR "age of first use" OR } \\
\text { "early initiation" OR "early age" OR "age of onset" }\end{array}$ \\
\hline $\begin{array}{l}\text { "Sexual debut" OR "sexual intercourse" OR "sexual initiation" } \\
\text { OR "risky sexual behavior" }\end{array}$ & AND & $\begin{array}{l}\text { "subsequent" OR "early initiation" OR "adolescence" OR "early } \\
\text { age" OR "age of onset" OR "age of first use" }\end{array}$ \\
\hline
\end{tabular}

with earlier initiation of drug use behavior among youth, as detailed below.

\subsection{Initiation of Substance Use and Concurrent Health Risks.} Miller et al. explored factors associated with IDU initiation before age 16 among 542 IDUs [81]. Thirty-eight percent of the sample initiated IDU prior to age 16. There was also an association between earlier initiation of injection drug use and the following variables: gender (being female), identifying as a sex worker, using other drugs, and having a history of criminal justice system involvement. Early drinkers more likely to report subsequent alcohol problems, unprotected sexual intercourse, multiple partners, and being drunk or high during sexual intercourse. Likewise, a study conducted in Canada assessed the circumstances surrounding the initiation of injection drug use among 560 street-recruited youth (median age of drug use debut was age 13; median age of IDU debut was age 17) and found a significant association between age of first drug use and history of IDU [74]. A study conducted in Russia assessed 558 IDUs and their non-IDUs sexual partners and found that the initiation of alcohol use at a younger age (mean $=14.2$ years) was related to an earlier onset of coitarche (mean $=15.5$ years) and a younger age of first drug use (mean $=16.8$ years) [6]. Thus, a significant correlation was found between age of first alcohol use and the age at first sexual intercourse as well as the likelihood for having multiple sexual partners and age of initiating injection drug use behavior.

A cross-sectional behavioral survey that evaluated 805 street-based adolescents in the Ukraine reported a pattern of elevated HIV risk stemming from both unprotected sex and injection drug use [100]. Almost $75 \%$ of the sample of adolescents had experienced sexual behavior debut before the age of 15. Among those who reported injecting drugs within the past month, $44 \%$ had shared needles at least once and reported lower levels of condom use. These studies built on earlier studies in this area by examining health outcomes linked with injection drug use initiation among youth from diverse samples.

Noninjection drug use also shares a strong linkage with early coital debut across a vast ethnic and national landscape. Using data gathered from seven national and three local surveys, the National Campaign to Prevent Teen Pregnancy's Research Task Force found that, compared to delayed sexual activity, early sexual activity among young US teens has been linked to a greater number of sexual partners over time. In addition, these surveys found that sexually experienced youth aged 14 and younger are much more likely to smoke, use drugs and alcohol, and participate in delinquent activities than their inexperienced peers [101], though the precise sequence of behaviors remains uncertain. Other national survey data gathered in the USA show that girls who had begun smoking marijuana by age 14 or cigarettes by age 12 were significantly more likely to be pregnant by age 15 , though it is plausible that these predictors were moderated by some common underlying risk factors [66]. In a cross-sectional sample of 15to 21-year-old male and female vocational students in Thailand, recent cigarette smoking, alcohol consumption, and illicit substance use were all strongly associated with earlier onset of sexual intercourse for males, though whether or not experimentation with drugs predisposed these individuals to engage in risky sexual behavior was unclear [79]. Additionally, a 2009 survey assessing risk behavior of Mississippi public high school students [37] found similar associations between drinking alcohol, smoking cigarettes, and using marijuana or other drugs and early sexual initiation. Black respondents, it was found, were more likely to report early sexual initiation.

\subsection{Debut of Risk Behaviors and Subsequent HIV Risk Out-} comes. Although the majority of studies examined associations among concurrent health risk variables, we also identified an expanding body of relevant literature that focused on the influence of early risk behaviors (e.g., sexual activity and drug use) on HIV risk behaviors at later points in life. In addition to the lingering effects of early sexual experiences on a wide range of health outcomes discussed earlier [33], early coitus has an association with HIV risk behaviors, specifically, later in life in a range of diverse contexts and populations.

In a large population-based study of over 23,000 Danish men aged 18-45, Buttmann et al. found that those with early sexual debuts (i.e., sexual activity before age 14) were more likely to have subsequently engaged in risky sexual behaviour (i.e., having 8 or more lifetime sexual partners and two or more current partners) than older debuters [22]. This association was also evident in a cross-sectional survey of 15-18-year-old adolescent boys in Tehran; of those who were sexually experienced, about $15 \%$ had sexual debuts by age 12 , $35 \%$ by age 14 , and $55 \%$ by age 15 . Moreover, early sexual debut was a predictor of multiple sexual partners in one's lifetime. A similar pattern was shown in a 3-year longitudinal study of male and female urban minority adolescents in 
the USA; early initiators (those who had engaged in sex by 7 th grade) were more likely than later initiators (those who had abstained by the end of middle school) have reported multiple sex partners, being involved in a pregnancy, forcing a partner to have sex, having frequent intercourse, and having sex while intoxicated or under the influence [30]. The same study, however, noted significant gender differences in these outcomes; early female initiators were four times more likely to be involved in a pregnancy and were half as likely to report consistent condom use versus their male counterparts, while males were more likely than females to report having had at least four sexual partners.

The association between early sexual debut and subsequent risky behavior or HIV infection is also seen in studies with exclusively female samples [70, 75, 97]. One populationbased study of nearly 65,000 women in four Nordic countries illustrated that young age of first sexual intercourse was highly associated with reporting risk-taking behaviors. Among the sample of women aged 18 to 45 , young age of first intercourse (age 14 or younger) was highly associated with risk-taking behaviors, such as a greater number of lifetime sexual partners, recent partners, and history of STIs [31].

Fatusi and Wang investigated the association between early coital debut and STIs among a nationally representative sample of 15- to 24-year-old males in Nigeria and found that early sexual debut (sexual intercourse before age 16) had a significant independent association with self-reported STIs [26]. In addition, early sexual initiators were significantly more likely to have sex with casual or commercial partners and multiple partners and less likely to use condoms. Having multiple sexual partners, in this case, mediated the association between age of sexual debut and subsequent STI [26]. Similar findings that clearly show a strong association between early sexual debut and subsequent STIs have also been documented in mixed-gender samples [77] and among gay men [29], while the early sexual debut and multiple partners correlation has been shown among South African youth [35]. Another study of 15- to 24-year-old males in South Africa reported findings consistent with the following: those who initiated sex before age 15 were more likely to report no condom use and a casual partner at first sex. Furthermore, early sexual debut was strongly associated with having more than three partners within the past three years, thus placing them at higher risk for HIV and other STIs [28].

In one study, Fuller et al. focused on both sexual and IDU debut behavior and examined the factors associated with injection initiation during adolescence (i.e., age 21 or younger) compared with young adulthood (i.e., older than age 21) among 226 street-recruited IDUs in the Baltimore, MD, area [72]. The overall median age of IDU initiation was age 23 and $40 \%$ of the sample reported initiating IDU during adolescence. Those who reported initiating injection drug use during adolescence tended to demonstrate relatively rapid progression to IDU compared to those who initiated injection drug use as adults. Forty-two percent of study participants reported that their sexual debut occurred prior to age fourteen. Those who reported initiating IDU during adolescence were more likely to report having their first sexual experience prior to age 14 as well as having multiple sex partners in the previous six months [72].

In a later study, Fuller et al. evaluated predictors of age of injection drug use initiation and HIV-related risk behaviors among a similar population-144 IDUs in Baltimore, MD [61]. This study reported that race, neighborhood, and educational level were significant predictors of age of injection drug use initiation. In this study, the median age at initiation of IDU was age 21. Fifty-one percent of the participants had initiated IDU during adolescence. Adolescent initiators were twice as likely as young adult initiators to report that their first sexual experience have taken place before they were 14 years of age. Adolescent-initiating IDUs were less likely than adult-initiating IDUs to report high-risk sex and injection behaviors, but more likely to report high-risk networks. Cheng et al. explored risk factors associated with the initiation of injection drug use among 2,231 injectors in Northern Thailand [45]. The analyses indicated that the age of drug initiation was negatively associated with the risk of injection initiation such that the older the age of initiation of any type of drug use, the lower the risk of initiating injection drug use. Likewise, in a study of IDUS in southern Thailand, HIV status was also correlated with an earlier age of injection initiation $[90,95]$ and injecting at drug debut $[90]-$ underscoring the importance of drug use debut as a salient HIV risk factor.

Muga and colleagues assessed HIV-related outcomes among 1,111 IDUs in Spain and reported that both age of drug use debut and duration of injection drug use were associated with participants contracting HIV [84]. Subramaniam and Stitzer evaluated adolescents (aged 14-18) who reported substance abuse and their subsequent risk for HIV [93]. Approximately half of injection heroin users in the group reported sharing needles or "works" during this particular period of time, leaving them highly susceptible to Hepatitis$\mathrm{C}$ and HIV infection. Forty percent of the total sample population, however, including both opioid- and heroinusers, engaged in HIV risk behaviors such as having multiple sexual partners and always having unprotected sex. Likewise, Parviz et al. focused on drug- and sex-related risk behavior outcomes among 242 IDUs in Pakistan and found that a slightly younger age of first injection (age 25 versus age 28) was associated with subsequent drug-related HIV risk behavior (i.e., receptive needle sharing) [88]. Forty-seven percent of those who participated in the study engaged in receptive needle sharing, $22 \%$ had sexual intercourse-of whom only 7\% used condoms-and none had cleaned their needles with bleach.

More recently, Dillon et al. explored the associations among age of sexual behavior debut and sexual risk behaviors among 158 predominantly Latina immigrants (mean age: 27.2 years) living in Miami, FL. The following variables were associated with a younger age of sexual behavior debut: a greater number of sexual partners, more frequent sex-related alcohol or drug use, and greater levels of intoxication from alcohol or drugs during sex [25]. Dorjgochoo et al. also examined the associations between various behavioral factors and HIV status among 3,391 sexually active Haitians [69]. The mean age of sexual debut was age 16.5 for females and 
age 14.6 for males. HIV infection for female participants was associated with years of sexual activity, confirmed/suspected STI in females, and suspected STI in partners or suspicion that partners had outside sexual partners; HIV infection among male participants was associated with drug use and sexual debut with an unknown person. Interestingly, later sexual debut was not protective of HIV infection among women or men in this sample. Moreover, sexual debut after age 16 was positively associated with HIV infection in males. In contrast, Medhi et al. focused on factors associated with HIV serostatus among 426 female sex workers (mean age of 25.7 years) in India and found in a multivariate analysis that $\mathrm{HIV}$-infected status was significantly associated with lifetime injection drug use, initiating sexual intercourse before age 15 and testing positive for one or more STIs [80]. Likewise, Gore-Felton et al. showed in a sample of 16- to 25-year-old male and female IDUs in Russia (mean sexual debut ages 14.84 and 15.50 , resp.) that young age of sexual initiation was significantly associated with sexual risk behaviors in the past 30 days for men but not women [73]. This suggests a strong association between young coital debut and subsequent risky sexual and injection drug use behaviors. Taken together, studies from diverse geographic locations and populations suggest that earlier risk behaviors-including sexual activity and drug use-are significantly associated with HIV risk behaviors at later points in life.

\section{Discussion}

We reviewed studies that included data on the initiation of sexual and drug use behavior and concurrent and subsequent health risk behaviors. Although the majority of studies were cross-sectional and included information linking recent risk behaviors among youth, we also uncovered evidence of a linkage between early initiation of various risk behaviors and health risk behaviors later in life. Not surprisingly, the pattern of outcomes tend to show that the early initiation of sexual behavior and substance use are related to a range of other recent health risks, such as various STIs [26, 27, 33, 67], HIV [75], SUDs such as cannabis use disorders and alcohol use disorders $[60,102]$, psychiatric disorders including MDD [8], Hepatitis-C and cervical cancer [24], engaging in commercial sex exchange work [26, 71], poor school performance and conduct disorder [52], physical violence [65], receptive needle sharing [86], pregnancy $[27,66]$, and externalizing disorders [42]. In contrast, the longitudinal associations tend to be less clear cut based on the studies currently available.

The associations between sexual and drug debuts with contemporaneously occurring risk behaviors, as well as those occurring at later points in life, appear to be complex and therefore difficult to precisely capture. In the studies reported to date, it is also difficult to pinpoint the influence of sexual and substance use debuts as other risk factors-that particularly the initiation of drug and/or alcohol use-are often reported to occur concurrently. As indicated above, an early age of sexual initiation is associated with subsequent sexual risk behaviors, but also with subsequent risky drug use behavior [80] and substance use in general [42, 60, 103, 104].
Importantly, both types of risk behavior debuts have been linked to HIV infection [29, 69, 70, 75, 80, 81, 84, 90, 95, 97]. Likewise, the association of an early drug use debut and later risk behavior appears to be multidirectional, as subsequent risky substance use practices (e.g., needle sharing), sexual practices (e.g., multiple partners, transactional sex, lack of condom use), and substance use in general have all been linked. This crossover of risk behavior domains, thus, suggests that early initiation of either type of risk behavior can be associated with the other $[6,24,25,27,31,37,49,63-$ $65,76,78-80,89,98,103,104]$, and both might operate synergistically (e.g., drinking or illicit drug use coupled with unprotected sex [105]) as part of a tendency toward a generally riskier lifestyle.

The overall influence of earlier initiation of sexual activity tends to be negative but varies significantly across ethnicities and/or geographic location, socioeconomic status, gender [30], and sexual orientation, thus precluding universal generalizations, as might be expected. Despite disagreement among researchers about whether early sexual involvement fits into a larger constellation of generic "problem behaviors" or merely experimentation as a normative part of development [33, $106,107]$, theories suggest that sensation-seeking $[63,105]$, increased feelings of invulnerability, and risk-proneness-or a propensity to be attracted to potentially risky behaviorlikely play prominent roles in influencing early sexual debuts [14]. Adolescence, after all, is a period preceding full cognitive development and emotional maturity [108].

The larger cultural contexts in which these behaviors occur must be considered, as sexual and substance use norms and perceptions are often shaped by religious, national/regional, and social values. In many cultures, adolescent sexual activity is increasingly viewed as a normative aspect of developing responsible intimate relationships as teens mature into adulthood, rather than a delinquent behavior like drug use $[30,33,107]$. Consequently, the disparate cultural norms inherent in the vast array of countries, communities, and ethnic subgroups included in this review may be expected to differentially influence the trajectories of subsequent risk behaviors [62].

The age of sexual initiation carries serious implications for STI risk; early sexual debut potentially increases the duration of lifetime sexual exposure, allowing a relatively longer sexual career overall and, hence, more time for individuals with young debuts to accrue sexual partners, especially during adolescence, when relationships are often short in duration and changing sexual partners is more common [22, 26, 31] and risk-proneness is heightened [21]. The importance of considering the nature of and context in which initial sexual experiences occur cannot be overstated, as sexual coercion, sex under the influence, and rape are profoundly different sexual experiences than consensual intercourse within the context of a trusting, intimate relationship, for instance, and have profoundly different implications for influencing future risk behavior [32, 99]. Many studies simply were not designed to disentangle these important qualitative details nor the emotional context surrounding diverse experiences surrounding the first sexual intercourse. 


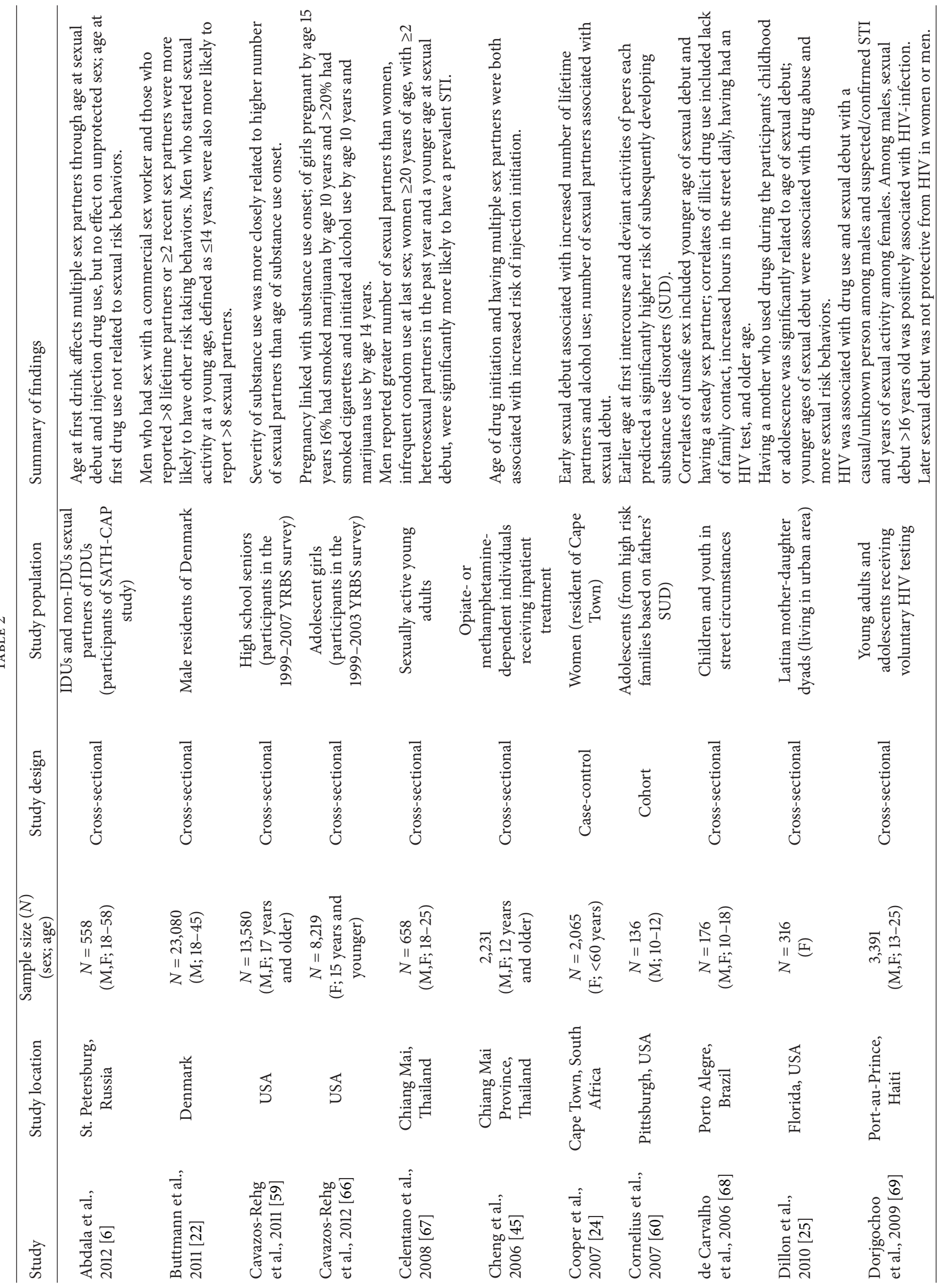




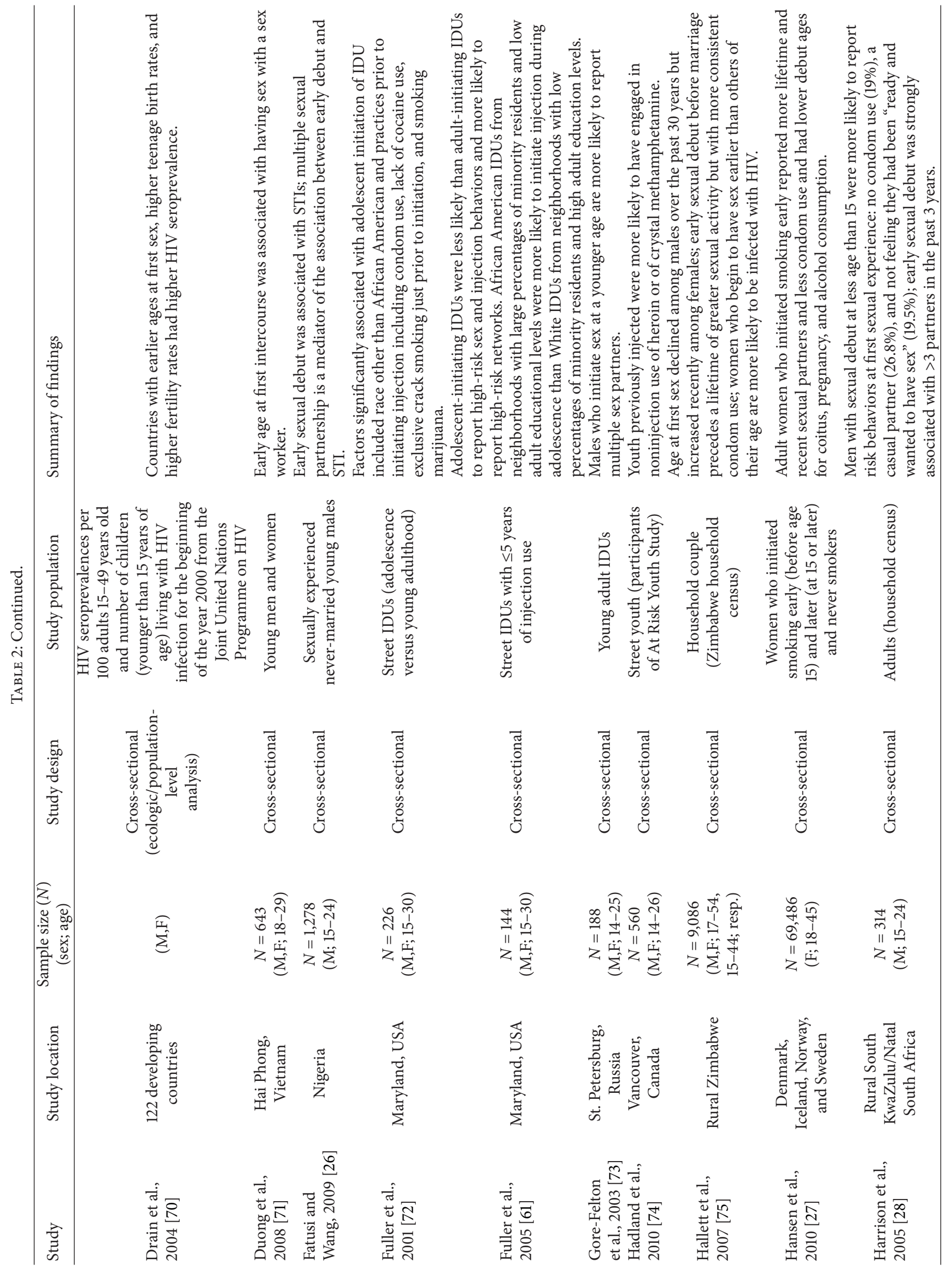




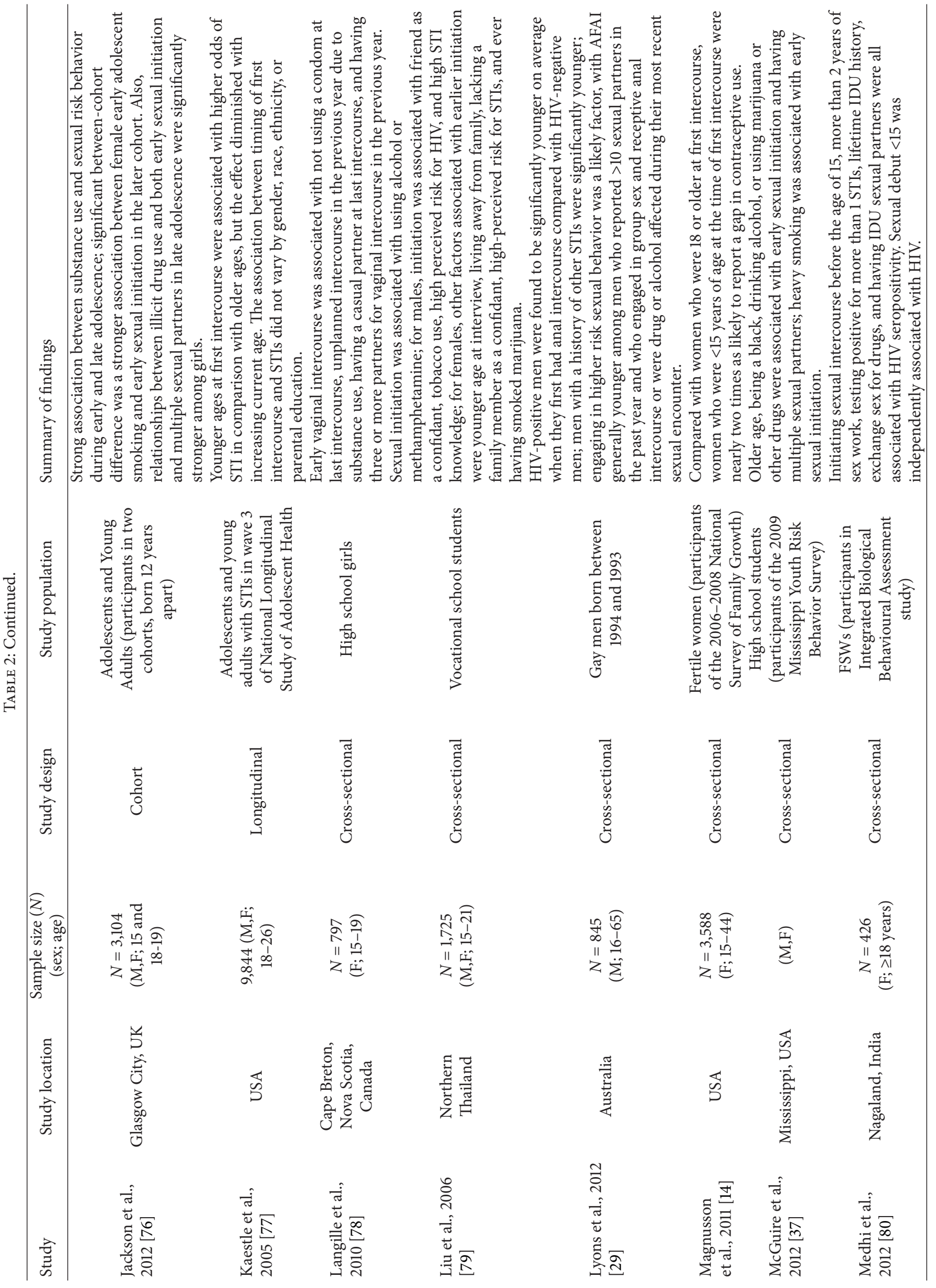




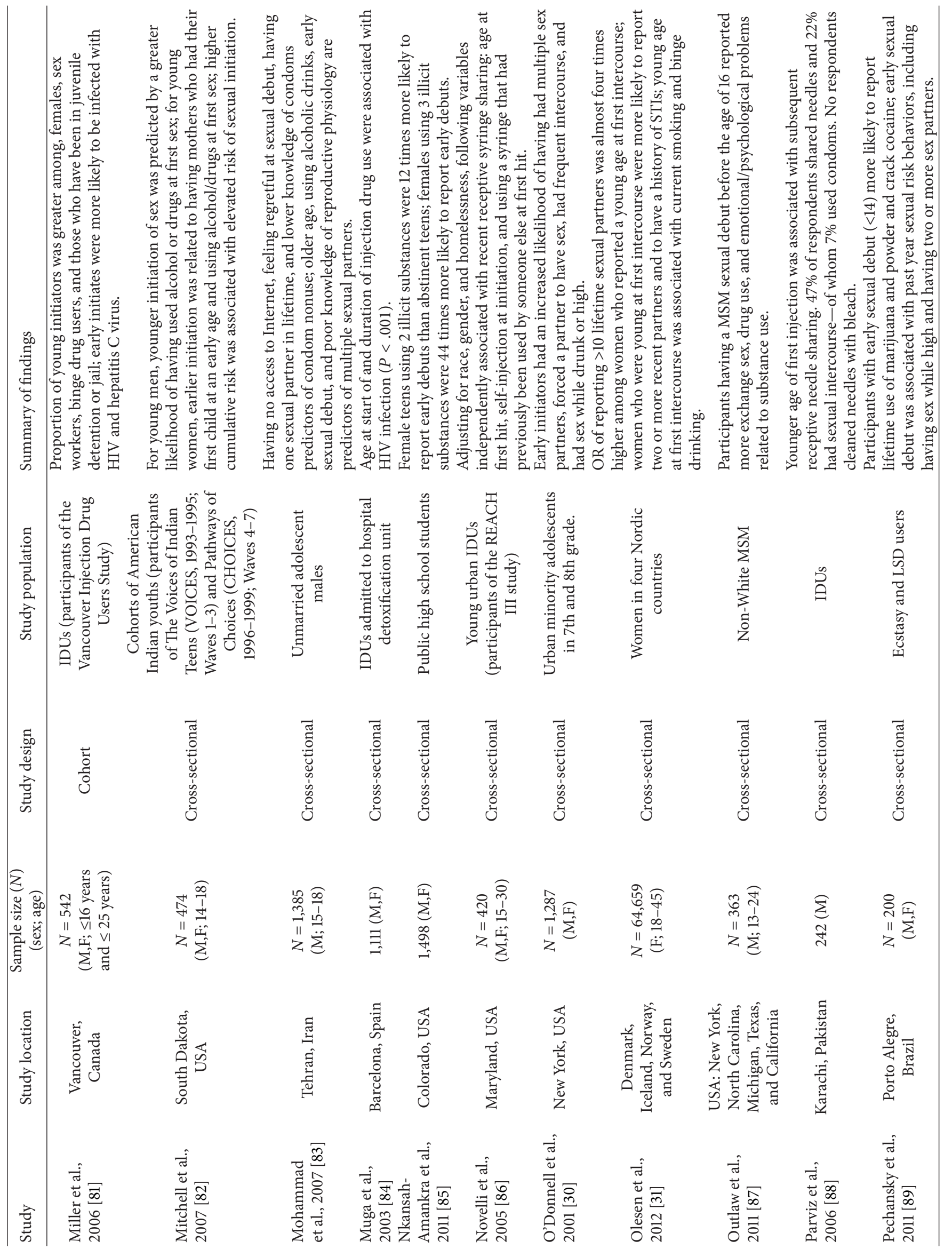




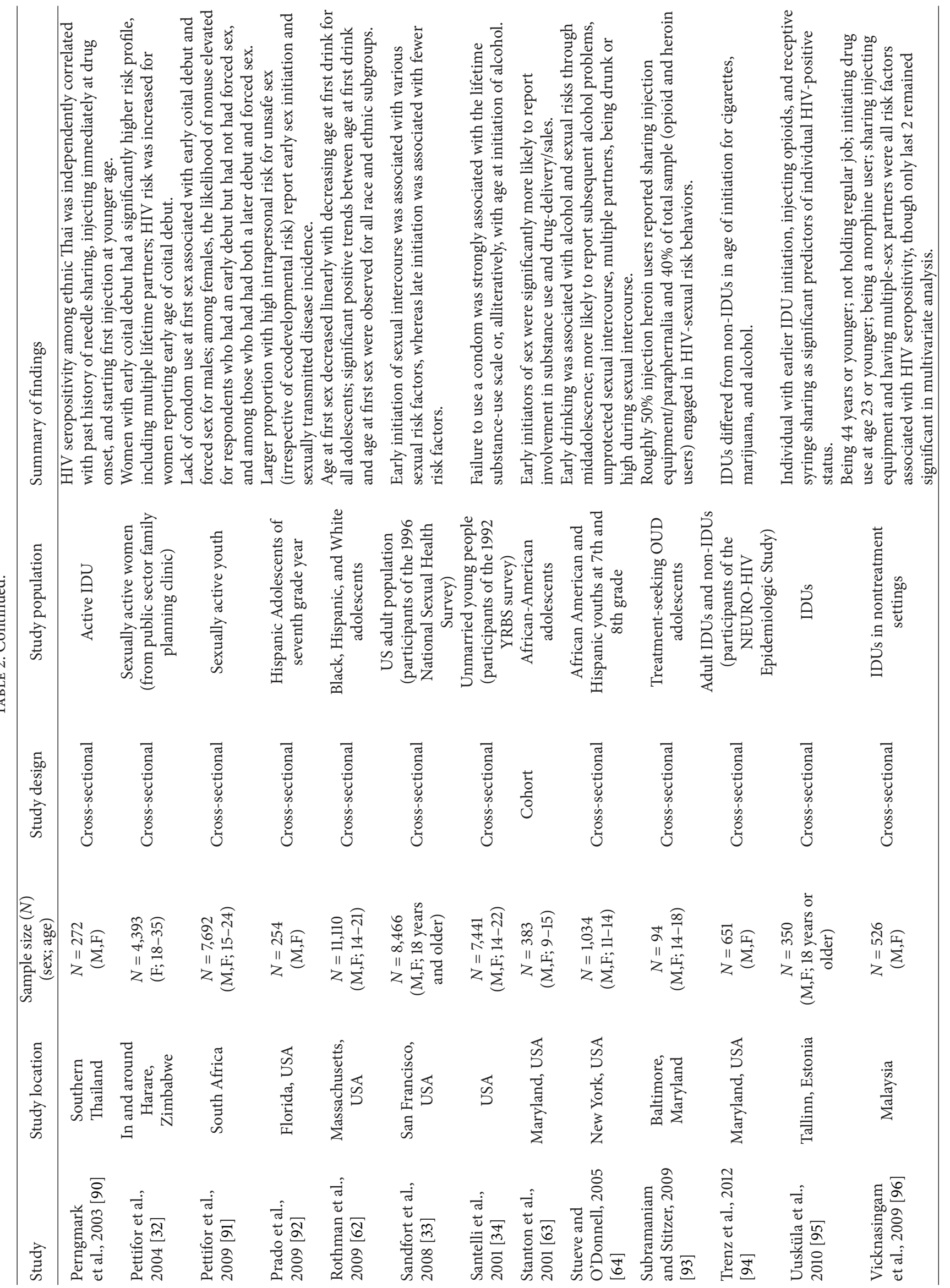




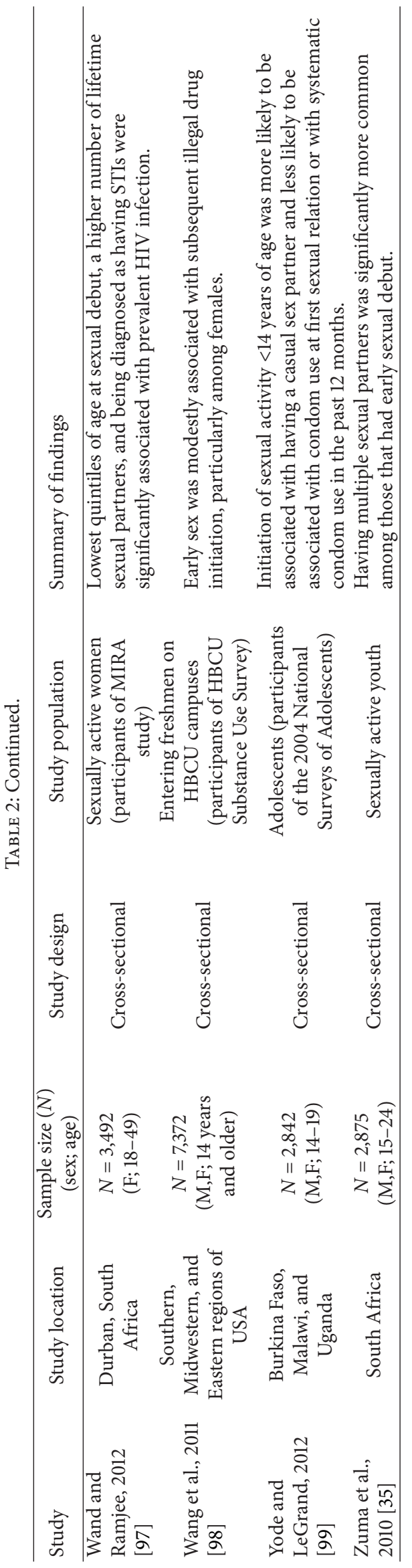


A similar rationale has been proffered to explain the link between early substance initiation and IDU behavior later in life. Earlier exposure and access to substances during a period of psychosocial development, marked by relatively rapid cognitive changes and strong peer influence, create a greater window of potential risk [94]. Additionally, poorer performance on executive functioning tasks among adolescent substance users suggest a reduced ability to control behavior, make healthy long-term decisions, and attend to environmental stimuli which may put individuals at greater risk for substance use later in life $[58,94]$. Thus, considered as a whole, studies to date indicate that early initiation of sexand drug-related behaviors may exert substantial influence on youth from diverse backgrounds and geographical regions and may set them on a different HIV risk trajectory relative to their counterparts who do not have an early debut of such behaviors.

4.1. Study Limitations. Some of the limitations of this systematic review should be acknowledged. First, the review was restricted to peer-reviewed journal articles published in English, which likely biased our collection toward primarily English-speaking countries. The search itself was restricted to one database, although this is unlikely to have been a major limitation as PubMed Central (PMC), with nearly 2.4 million biomedical articles, is the largest repository of fulltext open-access biomedical articles in the world. In addition, only abstracts were screened for this review to determine whether the study investigated the impact of early sexual and substance use debuts on HIV risk behavior outcomes. Thus, any secondary findings and analyses relevant to our topics of interest not mentioned within the abstracts may have been excluded from this review. Many behaviors were selfreported, often at much later time points, making response bias and social desirability potential limiting factors.

We should also add that, due to a reliance on crosssectional designs in many of the studies included, it is not possible to establish causal inferences and, hence, precludes any definitive interpretations regarding the processes by which sexual and substance use debuts independently lead to later risky behaviors or the precise sequence of their trajectories. Since certain antecedents and common underlying factors, such as PTSD and CSA (childhood sexual abuse), parental substance use history, peer influence, and the role of genetic predispositions to substance dependence were not the foci of most of the studies included in this literature review, disentangling these potential confounders was well beyond the scope of our review.

4.2. Future Directions. Despite the noted limitations, the findings of this study have implications for future interventions and HIV risk prevention programs. Of the Centers for Disease Control and Prevention's (CDC) 18 evidencebased HIV Risk Prevention Interventions targeting "highrisk youth," eight address both drug and sexual risk behaviors. Of those, however, five are designed for either nonsubstance dependent or precoital adolescents, and only two of which meet the CDC's best evidence criteria of showing empirical evidence that demonstrates a reduction in HIV/STD incidence, reduced HIV-related risk behaviors, reduction in HIV viral load, or improvement in HIV medication adherence behaviors. Thus, a need exists for innovative EBIs that optimally target high risk youth in a manner that prevents or disrupts the linkage between the initiation of sex- and drug-related behaviors and subsequent HIV risk. Screening adolescents for risk factors may also prove a potent preventative measure given the established association between early debuts of substance use, sexual intercourse, or both, as it could potentially obviate later secondary and tertiary prevention efforts.

Interventions that cross multiple domains of risk (i.e., focus on delaying the initiations of sexual behaviors and substance use and reducing harm following initiation) may have a larger impact than addressing either one by itself in reducing the risk for STD transmission, pregnancy, initiation of IDU, and HIV infection. Interventions are needed that focus on the associations between substance use, multiple sexual partners, failure to use condoms, and HIV infection and that stress the potential harms of alcohol and other substances on judgment and risk taking. Secondly, interventions should confront attitudes about condom use and sexual norms in a culturally competent and relevant manner-tailoring messages to fit within the target audience's larger religious, social, and cultural contexts [31, 62, 83]. A "one size fits all" approach would overlook the diverse findings of the studies reviewed that vary among different ethnic groups and communities of disparate socioeconomic statuses. Environmental context, race, sexual orientation [29, 87], and gender must all be considered when designing behavioral interventions targeting adolescents [61].

Lastly, future prevention interventions should target younger, precoital adolescents in late elementary and early middle school who are cognitively susceptible to experimenting with a range of risk-taking behaviors. Early screening to assess for behaviors such as drinking and cigarette smoking might help to quickly identify those beginning to experiment and assist them in averting a trajectory with potentially deleterious health outcomes. Similarly, an efficacious assessment tool could provide an early warning sign to parents, school counselors, medical professionals, and other professionals in positions to provide proper education and counseling regarding the short- and long-term health consequences of initiating risky behaviors during adolescence.

\section{Appendix}

For more details see Table 2.

\section{References}

[1] B. M. Mathers, L. Degenhardt, B. Phillips et al., "Global epidemiology of injecting drug use and HIV among people who inject drugs: a systematic review," The Lancet, vol. 372, no. 9651, pp. 1733-1745, 2008.

[2] Centers for Disease Control and Prevention, Diagnoses of HIV Infection and AIDS in the United States and Dependent 
Areas, 2011, vol. 23 of HIV Surveillance Report, 2013, http://www.cdc.gov/hiv/pdf/statistics_2011_HIV_Surveillance_ Report_vol_23.pdf.

[3] B. J. Lohman and A. Billings, "Protective and risk factors associated with adolescent boys' early sexual debut and risky sexual behaviors," Journal of Youth and Adolescence, vol. 37, no. 6, pp. 723-735, 2008.

[4] D. K. Eaton, L. Kann, S. Kinchen et al., "Youth risk behavior surveillance-United States, 2011," Morbidity and Mortality Weekly Report, vol. 61, no. 4, pp. 1-162, 2012.

[5] P. A. Cavazos-Rehg, M. J. Krauss, E. L. Spitznagel et al., "Age of sexual debut among US adolescents," Contraception, vol. 80, no. 2, pp. 158-162, 2009.

[6] N. Abdala, N. B. Hansen, O. V. Toussova, T. V. Krasnoselskikh, A. P. Kozlov, and R. Heimer, "Age at first alcoholic drink as predictor of current HIV sexual risk behaviors among a sample of Injection Drug Users (IDUs) and non-IDUs who are sexual partners of IDUs, in St. Petersburg, Russia," AIDS and Behavior, vol. 16, no. 6, pp. 1597-1604, 2012.

[7] J. C. Anthony and K. R. Petronis, "Early-onset drug use and risk of later drug problems," Drug and Alcohol Dependence, vol. 40, no. 1, pp. 9-15, 1995.

[8] D. W. Brook, J. S. Brook, C. Zhang, P. Cohen, and M. Whiteman, "Drug use and the risk of major depressive disorder, alcohol dependence, and substance use disorders," Archives of General Psychiatry, vol. 59, no. 11, pp. 1039-1044, 2002.

[9] B. T. Conner, G. S. Hellemann, T. L. Ritchie, and E. P. Noble, "Genetic, personality, and environmental predictors of drug use in adolescents," Journal of Substance Abuse Treatment, vol. 38, no. 2, pp. 178-190, 2010.

[10] S. Hansell and H. R. White, "Adolescent drug use, psychological distress, and physical symptoms," Journal of Health and Social Behavior, vol. 32, no. 3, pp. 288-301, 1991.

[11] R. W. Hingson, J.-P. Assailly, and A. F. Williams, "Underage drinking: frequency, consequences, and interventions," Traffic Injury Prevention, vol. 5, no. 3, pp. 228-236, 2004.

[12] R. W. Hingson, T. Heeren, and M. R. Winter, "Age at drinking onset and alcohol dependence: age at onset, duration, and severity," Archives of Pediatrics and Adolescent Medicine, vol. 160, no. 7, pp. 739-746, 2006.

[13] K. M. King and L. Chassin, "A prospective study of the effects of age of initiation of alcohol and drug use on young adult substance dependence," Journal of Studies on Alcohol and Drugs, vol. 68, no. 2, pp. 256-265, 2007.

[14] B. M. Magnusson, S. W. Masho, and K. L. Lapane, "Adolescent and sexual history factors influencing reproductive control among women aged 18-44," Sexual Health, vol. 8, no. 1, pp. 95101, 2011.

[15] D. W. Zeigler, C. C. Wang, R. A. Yoast et al., “The neurocognitive effects of alcohol on adolescents and college students," Preventive Medicine, vol. 40, no. 1, pp. 23-32, 2005.

[16] A. L. Spriggs and C. T. Halpern, "Sexual debut timing and depressive symptoms in emerging adulthood," Journal of Youth and Adolescence, vol. 37, no. 9, pp. 1085-1096, 2008.

[17] S. Armour and D. L. Haynie, "Adolescent sexual debut and later delinquency," Journal of Youth and Adolescence, vol. 36, no. 2, pp. 141-152, 2007.

[18] A. Parkes, D. Wight, M. Henderson, and P. West, "Does early sexual debut reduce teenagers' participation in tertiary education? Evidence from the SHARE longitudinal study," Journal of Adolescence, vol. 33, no. 5, pp. 741-754, 2010.
[19] A.-K. Valle, E. Røysamb, J. Sundby, and K. I. Klepp, "Parental social position, body image, and other psychosocial determinants and first sexual intercourse among 15- and 16-year olds," Adolescence, vol. 44, no. 174, pp. 479-498, 2009.

[20] T. R. Raine, R. Jenkins, S. J. Aarons et al., "Sociodemographic correlates of virginity in seventh-grade black and Latino students," Journal of Adolescent Health, vol. 24, no. 5, pp. 304-312, 1999.

[21] B. M. Magnusson, S. W. Masho, and K. L. Lapane, "Early age at first intercourse and subsequent gaps in contraceptive use," Journal of Women's Health, vol. 21, no. 1, pp. 73-79, 2012.

[22] N. Buttmann, A. Nielsen, C. Munk, K. L. Liaw, and S. K. Kjaer, "Sexual risk taking behaviour: prevalence and associated factors. A population-based study of 22,000 Danish men," BMC Public Health, vol. 11, article 764, 2011.

[23] P. A. Cavazos-Rehg, M. J. Krauss, E. L. Spitznagel et al., "Type of contraception method used at last intercourse and associations with health risk behaviors among US adolescents," Contraception, vol. 82, no. 6, pp. 549-555, 2010.

[24] D. Cooper, M. Hoffman, H. Carrara et al., "Determinants of sexual activity and its relation to cervical cancer risk among South African women," BMC Public Health, vol. 7, article 341, 2007.

[25] F. R. Dillon, M. de La Rosa, S. J. Schwartz, P. Rojas, R. Duan, and R. M. Malow, "US Latina age of sexual debut: longterm associations and implications for HIV and drug abuse prevention," AIDS Care, vol. 22, no. 4, pp. 431-440, 2010.

[26] A. Fatusi and W. Wang, "Multiple sexual partnership mediates the association between early sexual debut and sexually transmitted infection among adolescent and young adult males in Nigeria," The European Journal of Contraception and Reproductive Health Care, vol. 14, no. 2, pp. 134-143, 2009.

[27] B. T. Hansen, S. K. Kjær, C. Munk et al., "Early smoking initiation, sexual behavior and reproductive health-a large population-based study of Nordic women," Preventive Medicine, vol. 51, no. 1, pp. 68-72, 2010.

[28] A. Harrison, J. Cleland, E. Gouws, and J. Frohlich, "Early sexual debut among young men in rural South Africa: heightened vulnerability to sexual risk?" Sexually Transmitted Infections, vol. 81, no. 3, pp. 259-261, 2005.

[29] A. Lyons, M. Pitts, J. Grierson, A. Smith, S. McNally, and M. Couch, "Age at first anal sex and HIV/STI vulnerability among gay men in Australia," Sexually Transmitted Infections, vol. 88, no. 4, pp. 252-257, 2012.

[30] L. O’Donnell, C. R. O’Donnell, and A. Stueve, "Early sexual initiation and subsequent sex-related risks among urban minority youth: the reach for health study," Family Planning Perspectives, vol. 33, no. 6, pp. 268-275, 2001.

[31] T. B. Olesen, K. E. Jensen, M. Nygård et al., "Young age at first intercourse and risk-taking behaviours-a study of nearly 65000 women in four Nordic countries," European Journal of Public Health, vol. 22, no. 2, pp. 220-224, 2012.

[32] A. E. Pettifor, A. van der Straten, M. S. Dunbar, S. C. Shiboski, and N. S. Padian, "Early age of first sex: a risk factor for HIV infection among women in Zimbabwe," AIDS, vol. 18, no. 10, pp. 1435-1442, 2004.

[33] T. G. M. Sandfort, M. Orr, J. S. Hirsch, and J. Santelli, "Longterm health correlates of timing of sexual debut: results from a national US study," American Journal of Public Health, vol. 98, no. 1, pp. 155-161, 2008.

[34] J. S. Santelli, L. Robin, N. D. Brener, and R. Lowry, "Timing of alcohol and other drug use and sexual risk behaviors among 
unmarried adolescents and young adults," Family Planning Perspectives, vol. 33, no. 5, pp. 200-205, 2001.

[35] K. Zuma, G. Setswe, T. Ketye, T. Mzolo, T. Rehle, and N. Mbelle, "Age at sexual debut: a determinant of multiple partnership among South African youth," African Journal of Reproductive Health, vol. 14, no. 2, pp. 47-54, 2010.

[36] M. Durbin, R. J. DiClemente, D. Siegel, F. Krasnovsky, N. Lazarus, and T. Camacho, "Factors associated with multiple sex partners among junior high school students," Journal of Adolescent Health, vol. 14, no. 3, pp. 202-207, 1993.

[37] J. McGuire, B. Wang, and L. Zhang, "Substance use and sexual risk behaviors among Mississippi public high school students," Journal of the Mississippi State Medical Association, vol. 53, no. 10, pp. 323-328, 2012.

[38] S. N. Seidman, W. D. Mosher, and S. O. Aral, "Predictors of high-risk behavior in unmarried American women: adolescent environment as risk factor," Journal of Adolescent Health, vol. 15, no. 2, pp. 126-132, 1994.

[39] S. A. Burgard and S. M. Lee-Rife, "Community characteristics, sexual initiation, and condom use among young black South Africans," Journal of Health and Social Behavior, vol. 50, no. 3, pp. 293-309, 2009.

[40] A. Agrawal, J. D. Grant, M. Waldron et al., "Risk for initiation of substance use as a function of age of onset of cigarette, alcohol and cannabis use: findings in a Midwestern female twin cohort," Preventive Medicine, vol. 43, no. 2, pp. 125-128, 2006.

[41] S. Behrendt, H.-U. Wittchen, M. Höfler, R. Lieb, and K. Beesdo, "Transitions from first substance use to substance use disorders in adolescence: is early onset associated with a rapid escalation?" Drug and Alcohol Dependence, vol. 99, no. 1-3, pp. 68-78, 2009.

[42] S. Behrendt, K. Beesdo-Baum, M. Höfler et al., "The relevance of age at first alcohol and nicotine use for initiation of cannabis use and progression to cannabis use disorders," Drug and Alcohol Dependence, vol. 123, no. 1-3, pp. 48-56, 2011.

[43] N. Breslau, N. Fenn, and E. L. Peterson, "Early smoking initiation and nicotine dependence in a cohort young adults," Drug and Alcohol Dependence, vol. 33, no. 2, pp. 129-137, 1993.

[44] A. F. Buchmann, B. Schmid, D. Blomeyer et al., "Drinking against unpleasant emotions: possible outcome of early onset of alcohol use?” Alcoholism, vol. 34, no. 6, pp. 1052-1057, 2010.

[45] Y. Cheng, S. G. Sherman, N. Srirat et al., "Risk factors associated with injection initiation among drug users in Northern Thailand," Harm Reduction Journal, vol. 3, article 10, 2006.

[46] D. A. Dawson, R. B. Goldstein, S. Patricia Chou, W. June Ruan, and B. F. Grant, "Age at first drink and the first incidence of adult-onset DSM-IV alcohol use disorders," Alcoholism, vol. 32, no. 12, pp. 2149-2160, 2008.

[47] D. J. DeWit, E. M. Adlaf, D. R. Offord, and A. C. Ogborne, "Age at first alcohol use: a risk factor for the development of alcohol disorders," The American Journal of Psychiatry, vol. 157, no. 5, pp. 745-750, 2000.

[48] P. L. Ellickson, J. S. Tucker, D. J. Klein, and H. Saner, "Antecedents and outcomes of marijuana use initiation during adolescence," Preventive Medicine, vol. 39, no. 5, pp. 976-984, 2004.

[49] K. Poikolainen, A. Tuulio-Henriksson, T. Aalto-Setälä, M. Marttunen, T. Anttila, and J. Lönnqvist, "Correlates of initiation to cannabis use: a 5-year follow-up of 15-19-year-old adolescents," Drug and Alcohol Dependence, vol. 62, no. 3, pp. 175-180, 2001.
[50] J. Abelson, C. Treloar, J. Crawford, S. Kippax, I. van Beek, and J. Howard, "Some characteristics of early-onset injection drug users prior to and at the time of their first injection," Addiction, vol. 101, no. 4, pp. 548-555, 2006.

[51] B. Brands, J. Blake, B. Sproule, D. Gourlay, and U. Busto, "Prescription opioid abuse in patients presenting for methadone maintenance treatment," Drug and Alcohol Dependence, vol. 73, no. 2, pp. 199-207, 2004.

[52] Y.-I. Hser, C. E. Grella, C. Collins, and C. Teruya, "Drug-use initiation and conduct disorder among adolescents in drug treatment," Journal of Adolescence, vol. 26, no. 3, pp. 331-345, 2003.

[53] C. S. Meade, L. J. McDonald, and R. D. Weiss, "HIV risk behavior in opioid dependent adults seeking detoxification treatment: an exploratory comparison of heroin and oxycodone users," The American Journal on Addictions, vol. 18, no. 4, pp. 289-293, 2009.

[54] M. L. Schoeneberger, T. K. Logan, and C. G. Leukefeld, "Age differences in HIV risk behaviors and drug treatment utilization among drug users in Kentucky," Substance Use and Misuse, vol. 36, no. 6-7, pp. 867-925, 2001.

[55] B. Sproule, B. Brands, S. Li, and L. Catz-Biro, "Changing patterns in opioid addiction: characterizing users of oxycodone and other opioids," Canadian Family Physician, vol. 55, no. 1, pp. 68.e5-69.e5, 2009.

[56] C. Guerri and M. Pascual, "Mechanisms involved in the neurotoxic, cognitive, and neurobehavioral effects of alcohol consumption during adolescence," Alcohol, vol. 44, no. 1, pp. 15$26,2010$.

[57] J. D. Grant, J. F. Scherrer, M. T. Lynskey et al., "Adolescent alcohol use is a risk factor for adult alcohol and drug dependence: evidence from a twin design," Psychological Medicine, vol. 36, no. 1, pp. 109-118, 2006.

[58] L. M. Squeglia, J. Jacobus, and S. F. Tapert, "The influence of substance use on adolescent brain development," Clinical EEG and Neuroscience, vol. 40, no. 1, pp. 31-38, 2009.

[59] P. A. Cavazos-Rehg, M. J. Krauss, E. L. Spitznagel, M. Schootman, L. B. Cottler, and L. J. Bierut, "Number of sexual partners and associations with initiation and intensity of substance use," AIDS and Behavior, vol. 15, no. 4, pp. 869-874, 2011.

[60] J. R. Cornelius, D. B. Clark, M. Reynolds, L. Kirisci, and R. Tarter, "Early age of first sexual intercourse and affiliation with deviant peers predict development of SUD: a prospective longitudinal study," Addictive Behaviors, vol. 32, no. 4, pp. 850854, 2007.

[61] C. M. Fuller, L. N. Borrell, C. A. Latkin et al., "Effects of race, neighborhood, and social network on age at initiation of injection drug use," American Journal of Public Health, vol. 95, no. 4, pp. 689-695, 2005.

[62] E. F. Rothman, L. A. Wise, E. Bernstein, and J. Bernstein, "The timing of alcohol use and sexual initiation among a sample of black, hispanic, and white adolescents," Journal of Ethnicity in Substance Abuse, vol. 8, no. 2, pp. 129-145, 2009.

[63] B. Stanton, X. Li, L. Cottrell, and L. Kaljee, "Early initiation of sex, drug-related risk behaviors, and sensation-seeking among urban, low-income African-American adolescents," Journal of the National Medical Association, vol. 93, no. 4, pp. 129-138, 2001.

[64] A. Stueve and L. N. O'Donnell, "Early alcohol initiation and subsequent sexual and alcohol risk behaviors among urban youths," American Journal of Public Health, vol. 95, no. 5, pp. 887-893, 2005. 
[65] M. Makenzius and M. Larsson, "Early onset of sexual intercourse is an indicator for hazardous lifestyle and problematic life situation," Scandinavian Journal of Caring Sciences, vol. 27, no. 1, pp. 20-26, 2013.

[66] P. A. Cavazos-Rehg, M. J. Krauss, E. L. Spitznagel, M. Schootman, L. B. Cottler, and L. J. Bierut, "Brief report: pregnant by age 15 years and substance use initiation among US adolescent girls," Journal of Adolescence, vol. 35, no. 5, pp. 1393-1397, 2012.

[67] D. D. Celentano, B. Sirirojn, C. G. Sutcliffe et al., "Sexually transmitted infections and sexual and substance use correlates among young adults in Chiang Mai, Thailand," Sexually Transmitted Diseases, vol. 35, no. 4, pp. 400-405, 2008.

[68] F. T. de Carvalho, L. Neiva-Silva, M. C. Ramos et al., "Sexual and drug use risk behaviors among children and youth in street circumstances in Porto Alegre, Brazil," AIDS and Behavior, vol. 10, supplement 1, pp. S57-S66, 2006.

[69] T. Dorjgochoo, F. Noel, M. M. Deschamps et al., "Risk factors for HIV infection among haitian adolescents and young adults seeking counseling and testing in port-au-prince," Journal of Acquired Immune Deficiency Syndromes, vol. 52, no. 4, pp. 498508, 2009.

[70] P. K. Drain, J. S. Smith, J. P. Hughes, D. T. Halperin, and K. K. Holmes, "Correlates of national HIV seroprevalence: an ecologic analysis of 122 developing countries," Journal of Acquired Immune Deficiency Syndromes, vol. 35, no. 4, pp. 407420, 2004.

[71] C. T. Duong, T. H. Nguyen, T. T. H. Hoang et al., "Sexual risk and bridging behaviors among young people in Hai Phong, Vietnam," AIDS and Behavior, vol. 12, no. 4, pp. 643-651, 2008.

[72] C. M. Fuller, D. Vlahov, A. M. Arria, D. C. Ompad, R. Garfein, and S. A. Strathdee, "Factors associated with adolescent initiation of injection drug use," Public Health Reports, vol. 116, supplement 1, pp. 136-145, 2001.

[73] C. Gore-Felton, A. M. Somlai, E. G. Benotsch, J. A. Kelly, D. Ostrovski, and A. Kozlov, "The influence of gender on factors associated with HIV transmission risk among young Russian injection drug users," The American Journal of Drug and Alcohol Abuse, vol. 29, no. 4, pp. 881-894, 2003.

[74] S. E. Hadland, T. Kerr, B. D. L. Marshall et al., "Non-Injection drug use patterns and history of injection among street youth," European Addiction Research, vol. 16, no. 2, pp. 91-98, 2010.

[75] T. B. Hallett, J. J. C. Lewis, B. A. Lopman et al., "Age at first sex and HIV infection in rural Zimbabwe," Studies in Family Planning, vol. 38, no. 1, pp. 1-10, 2007.

[76] C. Jackson, H. Sweeting, and S. Haw, "Clustering of substance use and sexual risk behaviour in adolescence: analysis of two cohort studies," BMJ Open, vol. 2, no. 1, Article ID e000661, 2012.

[77] C. E. Kaestle, C. T. Halpern, W. C. Miller, and C. A. Ford, "Young age at first sexual intercourse and sexually transmitted infections in adolescents and young adults," American Journal of Epidemiology, vol. 161, no. 8, pp. 774-780, 2005.

[78] D. B. Langille, M. Asbridge, G. Flowerdew, and M. Allen, "Associations of sexual risk-taking with having intercourse before 15 years in adolescent females in Cape Breton, Nova Scotia, Canada," Sexual Health, vol. 7, no. 2, pp. 199-204, 2010.

[79] A. Liu, P. Kilmarx, R. A. Jenkins et al., "Sexual initiation, substance use, and sexual behavior and knowledge among vocational students in Northern Thailand," International Family Planning Perspectives, vol. 32, no. 3, pp. 126-135, 2006.

[80] G. K. Medhi, J. Mahanta, R. S. Paranjape, R. Adhikary, N. Laskar, and P. Nqully, "Factors associated with HIV among female sex workers in a high HIV prevalent state of India," AIDS Care, vol. 24, no. 3, pp. 369-376, 2012.

[81] C. L. Miller, S. A. Strathdee, T. Kerr, K. Li, and E. Wood, "Factors associated with early adolescent initiation into injection drug use: implications for intervention programs," The Journal of Adolescent Health, vol. 38, no. 4, pp. 462-464, 2006.

[82] C. M. Mitchell, N. R. Whitesell, P. Spicer, J. Beals, and C. E. Kaufman, "Cumulative risk for early sexual initiation among American Indian youth: a discrete-time survival analysis," Journal of Research on Adolescence, vol. 17, no. 2, pp. 387-412, 2007.

[83] K. Mohammad, F. K. A. Farahani, M. R. Mohammadi et al., "Sexual risk-taking behaviors among boys aged 15-18 years in Tehran," Journal of Adolescent Health, vol. 41, no. 4, pp. 407-414, 2007.

[84] R. Muga, A. Sanvisens, J. M. Egea, J. Tor, and C. Rey-Joly, "Trends in human immunodeficiency virus infection among drug users in a detoxification unit," Clinical Infectious Diseases, vol. 37, supplement 5, pp. S404-S409, 2003.

[85] S. Nkansah-Amankra, A. Diedhiou, H. L. K. Agbanu, C. Harrod, and A. Dhawan, "Correlates of sexual risk behaviors among high school students in Colorado: analysis and implications for school-based HIV/AIDS programs," Maternal and Child Health Journal, vol. 15, no. 6, pp. 730-741, 2011.

[86] L. A. Novelli, S. G. Sherman, J. R. Havens, S. A. Strathdee, and M. Sapun, "Circumstances surrounding the first injection experience and their association with future syringe sharing behaviors in young urban injection drug users," Drug and Alcohol Dependence, vol. 77, no. 3, pp. 303-309, 2005.

[87] A. Y. Outlaw, G. Phillips, L. B. Hightow-Weidman et al., "Age of MSM sexual debut and risk factors: results from a multisite study of racial/ethnic minority YMSM living with HIV,' AIDS Patient Care and STDs, vol. 25, no. 1, pp. S23-S29, 2011.

[88] S. Parviz, Z. Fatmi, A. Altaf et al., "Background demographics and risk behaviors of injecting drug users in Karachi, Pakistan," International Journal of Infectious Diseases, vol. 10, no. 5, pp. 364-371, 2006.

[89] F. Pechansky, L. Remy, H. L. Surratt et al., "Age of sexual initiation, psychiatric symptoms, and sexual risk behavior among ecstasy and LSD users in Porto Alegre, Brazil: a preliminary analysis," Journal of Drug Issues, vol. 41, no. 2, pp. 217-232, 2011.

[90] P. Perngmark, D. D. Celentano, and S. Kawichai, "Risk factors for HIV infection among drug injectors in southern Thailand," Drug and Alcohol Dependence, vol. 71, no. 3, pp. 229-238, 2003.

[91] A. Pettifor, K. O’Brien, C. MacPhail, W. C. Miller, and H. Rees, "Early coital debut and associated HIV risk factors among young women and men in South Africa," International Perspectives on Sexual and Reproductive Health, vol. 35, no. 2, pp. 82-90, 2009.

[92] G. J. Prado, S. J. Schwartz, M. Maldonado-Molina et al., "Ecodevelopmental $\mathrm{x}$ intrapersonal risk: substance use and sexual behavior in Hispanic adolescents," Health Education and Behavior, vol. 36, no. 1, pp. 45-61, 2009.

[93] G. A. Subramaniam and M. A. Stitzer, "Clinical characteristics of treatment-seeking prescription opioid vs. heroin-using adolescents with opioid use disorder," Drug and Alcohol Dependence, vol. 101, no. 1-2, pp. 13-19, 2009.

[94] R. C. Trenz, M. Scherer, P. Harrell, J. Zur, A. Sinha, and W. Latimer, "Early onset of drug and polysubstance use as predictors of injection drug use among adult drug users," Addictive Behaviors, vol. 37, no. 4, pp. 367-372, 2012. 
[95] A. Uusküla, J. M. McMahon, M. Raag et al., "Emergent properties of HIV risk among injection drug users in Tallinn, Estonia: synthesis of individual and neighbourhood-level factors," Sexually Transmitted Infections, vol. 86, pp. iii79-iii84, 2010.

[96] B. Vicknasingam, S. Narayanan, and V. Navaratnam, "The relative risk of HIV among IDUs not in treatment in Malaysia," AIDS Care, vol. 21, no. 8, pp. 984-991, 2009.

[97] H. Wand and G. Ramjee, "The relationship between age of coital debut and HIV seroprevalence among women in Durban, South Africa: a cohort study," BMJ Open, vol. 2, no. 1, Article ID e000285, 2012.

[98] Y. Wang, C. Storr, D. C. Browne, and F. A. Wagner, "Early sexual experience and later onset of illegal drug use among African American students on HBCU campuses," Substance Use and Misuse, vol. 46, no. 4, pp. 543-551, 2011.

[99] M. Yode and T. LeGrand, "Association between age at first sexual relation and some indicators of sexual behaviour among adolescents," African Journal of Reproductive Health, vol. 16, no. 2, pp. 173-188, 2012.

[100] J. R. Busza, O. M. Balakireva, A. Teltschik et al., "Streetbased adolescents at high risk of HIV in Ukraine," Journal of Epidemiology and Community Health, vol. 65, no. 12, pp. 11661170, 2011.

[101] B. Albert, S. Brown, and C. M. Flanigan, 14 and Younger: The Sexual Behaviors of Young Adolescents, National Campaign to Prevent Teen Pregnancy, Washington, DC, USA, 2003.

[102] L. Degenhardt, W. T. Chiu, K. Conway et al., "Does the gateway matter? Associations between the order of drug use initiation and the development of drug dependence in the national comorbidity study replication," Psychological Medicine, vol. 39, no. 1, pp. 157-167, 2009.

[103] K. Peltzer, "Early sexual debut and associated factors among inschool adolescents in eight African countries," Acta Paediatrica, vol. 99, no. 8, pp. 1242-1247, 2010.

[104] A. K. Turner, C. Latkin, F. Sonenstein, and S. D. Tandon, "Psychiatric disorder symptoms, substance use, and sexual risk behavior among African-American out of school youth," Drug and Alcohol Dependence, vol. 115, no. 1-2, pp. 67-73, 2011.

[105] S. F. Tapert, G. A. Aarons, G. R. Sedlar, and S. A. Brown, "Adolescent substance use and sexual risk-taking behavior," Journal of Adolescent Health, vol. 28, no. 3, pp. 181-189, 2001.

[106] C. J. Sullivan, K. K. Childs, and D. O'Connell, "Adolescent risk behavior subgroups: an empirical assessment," Journal of Youth and Adolescence, vol. 39, no. 5, pp. 541-562, 2010.

[107] W. Udell, T. Sandfort, E. Reitz, H. Bos, and M. Dekovic, "The relationship between early sexual debut and psychosocial outcomes: a longitudinal study of dutch adolescents," Archives of Sexual Behavior, vol. 39, no. 5, pp. 1133-1145, 2010.

[108] K. Edgardh, "Sexual behaviour and early coitarche in a national sample of 17 year old Swedish girls," Sexually Transmitted Infections, vol. 76, no. 2, pp. 98-102, 2000. 


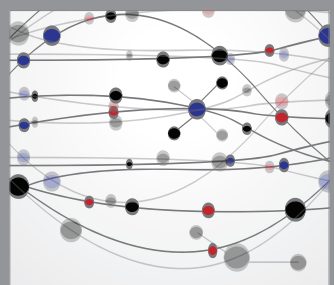

The Scientific World Journal
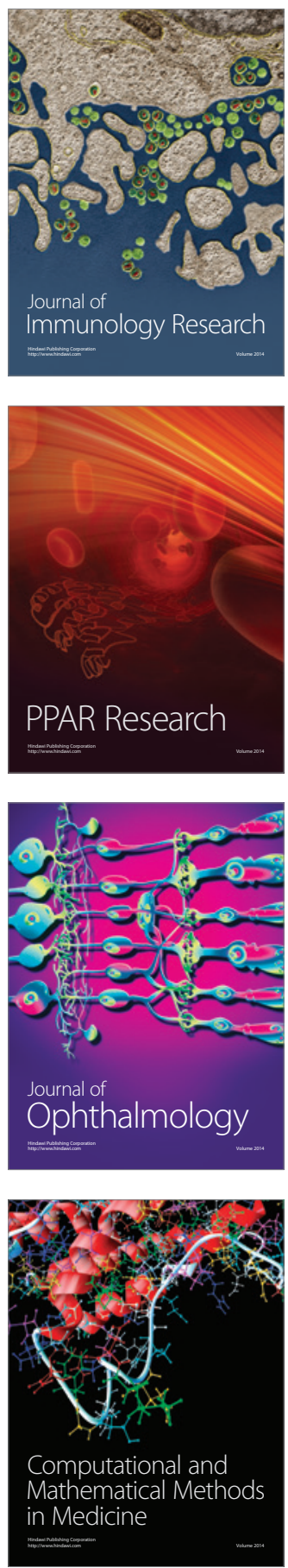

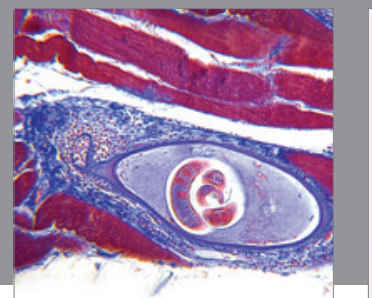

Gastroenterology

Research and Practice
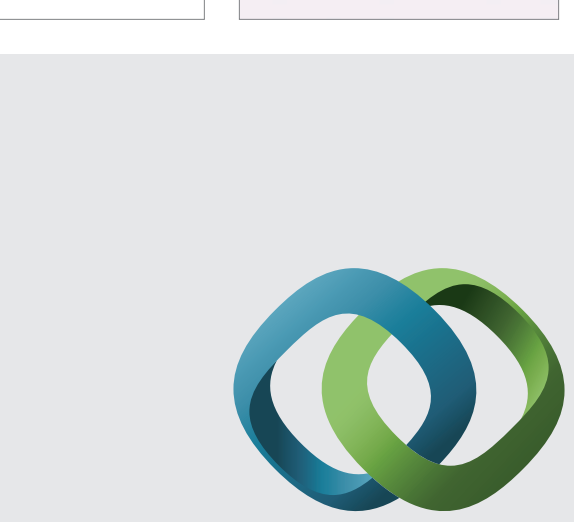

\section{Hindawi}

Submit your manuscripts at

http://www.hindawi.com
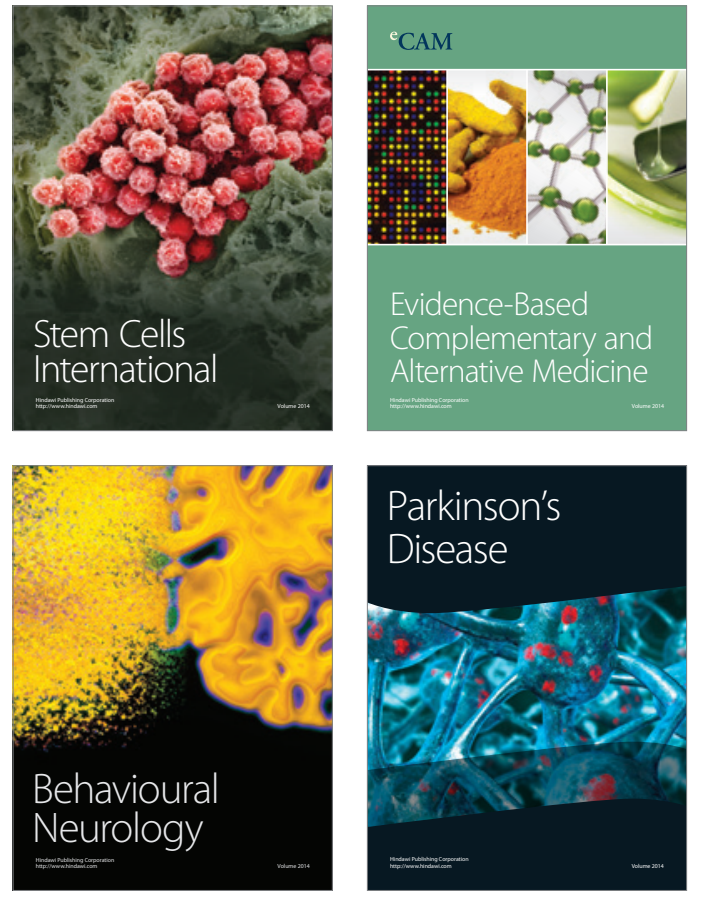
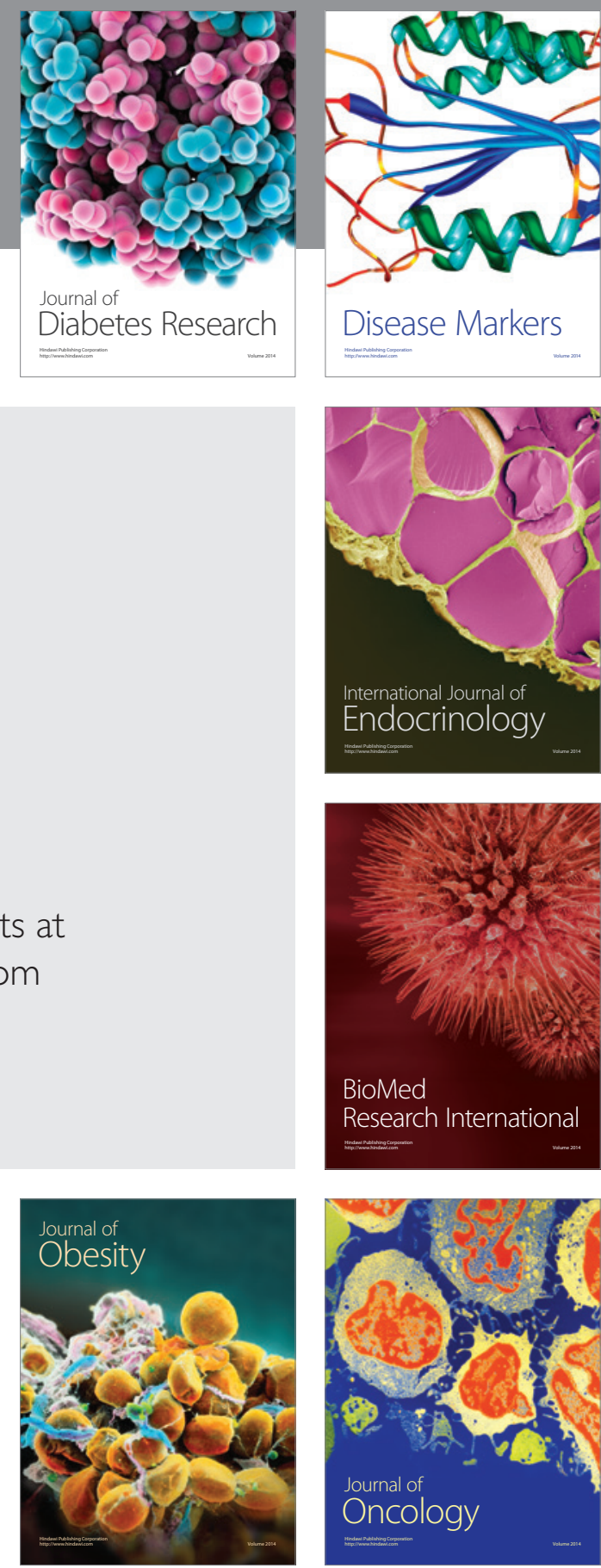

Disease Markers
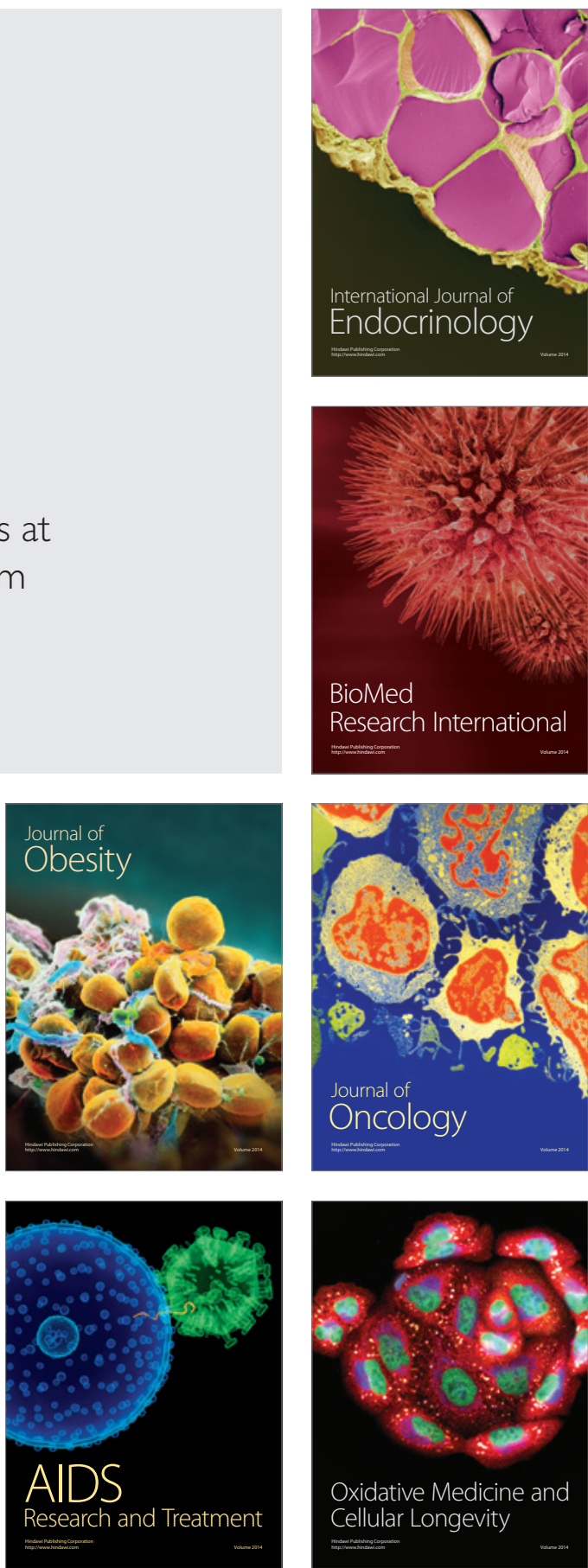